\title{
Intermediate-Temperature Creep Deformation and Microstructural Evolution of an Equiatomic FCC-Structured CoCrFeNiMn High-Entropy Alloy
}

\author{
Chengming Cao ${ }^{1}$, Jianxin Fu ${ }^{1}$, Tongwei Tong ${ }^{1}$, Yuxiao Hao ${ }^{1}$, Ping Gu ${ }^{1}$, Hai Hao ${ }^{2}$ \\ and Liangming Peng ${ }^{1, * \mathbb{D}}$ \\ 1 CAS Key Laboratory of Mechanical Behavior and Design of Materials, Department of Modern Mechanics, \\ School of Engineering Science, University of Science and Technology of China, Hefei 230027, China; \\ ccming@mail.ustc.edu.cn (C.C.); fjianxin@mail.ustc.edu.cn (J.F.); tw199309@mail.ustc.edu.cn (T.T.); \\ haozai@mail.ustc.edu.cn (Y.H.); guping@ustc.edu.cn (P.G.) \\ 2 School of Materials Science and Engineering, Dalian University of Technology, Dalian 116024, China; \\ haohai@dlut.edu.cn \\ * Correspondence: penglm@ustc.edu.cn; Tel.: +86-551-6360-6964
}

Received: 30 November 2018; Accepted: 9 December 2018; Published: 12 December 2018

\begin{abstract}
The tensile creep behavior of an equiatomic CoCrFeNiMn high-entropy alloy was systematically investigated over an intermediate temperature range $\left(500-600{ }^{\circ} \mathrm{C}\right)$ and applied stress (140-400 MPa). The alloy exhibited a stress-dependent transition from a low-stress region (LSR-region I) to a high-stress region (HSR-region II). The LSR was characterized by a stress exponent of 5 to 6 and an average activation energy of $268 \mathrm{~kJ} \mathrm{~mol}^{-1}$, whereas the HSR showed much higher corresponding values of $8.9-14$ and $380 \mathrm{~kJ} \mathrm{~mol}^{-1}$. Microstructural examinations on the deformed samples revealed remarkable dynamic recrystallization at higher stress levels. Dislocation jogging and tangling configurations were frequently observed in LSR and HSR at 550 and $600{ }^{\circ} \mathrm{C}$, respectively. Moreover, dynamic precipitates identified as $\mathrm{M}_{23} \mathrm{C}_{6}$ or a $\mathrm{Cr}$-rich $\sigma$ phase were formed along grain boundaries in HSR. The diffusion-compensated strain rate versus modulus-compensated stress data analysis implied that the creep deformation in both stress regions was dominated by stress-assisted dislocation climb controlled by lattice diffusion. Nevertheless, the abnormally high stress exponents in HSR were ascribed to the coordinative contributions of dynamic recrystallization and dynamic precipitation. Simultaneously, the barriers imposed by these precipitates and severe initial deformation were referred to so as to increase the activation energy for creep deformation.
\end{abstract}

Keywords: high entropy alloy; tensile creep behavior; microstructural evolution; creep mechanism

\section{Introduction}

High-entropy alloys (HEAs), as a novel type of material generally consisting of five or more principle elements, have attracted extensive attention in recent years because of their attractive crystallographic and mechanical properties [1-7]. Although it is anticipated that simple solid solution phases are easier to form rather than the intermetallic compounds or complex-ordered phases due to their high configurational entropy [8,9], only a few HEAs have exactly single and stable solid solution structures, among which CoCrFeNiMn alloy is widely concerned [10-14]. It possesses a single face-center-cubic (fcc) solid solution phase even after a series of thermomechanical processing $[15,16]$ and its constituent elements have more sluggish diffusion compared to other conventional alloys [17]. These characterizations contribute to excellent mechanical properties with a satisfactory combination between tensile strength and ductility $[18,19]$. Apart from previous investigations mainly focusing on its temperature dependence of strength $[20,21]$, which provided a fundamental understanding of 
the strengthening mechanism in fcc solid solution HEAs, recent reports have elucidated the thermally activated process, where dislocation lines overcome nanoscale clusters or short-range orders for controlling the deformation rate [22,23]. This intrinsic mechanism indicated effective heat-resistance during high-temperature plastic deformation processes. Owing to the aforementioned sluggish elemental diffusion, it is optimistic that the CoCrFeNiMn alloy will exhibit a promising perspective in high-temperature applications.

When referring to high-temperature performance for most alloy systems, creep resistance is one of the most important standards for service life and safety reliability of engineering structures. In particular, it is necessary to evaluate the stress exponents and activation energies to demonstrate the mechanism operative in the power-law creep deformation, as these two parameters are usually employed to predict the steady-state creep strain. However, only quite limited reports on tensile creep properties of HEAs at elevated temperatures have been available. The investigation on creep behavior of AlxCoCrFeNi $(x=0.15,0.60)$ alloys using the stress relaxation method [24] demonstrated a lower creep resistance for higher $\mathrm{Al}$ content alloy, which was attributed to the easier dislocation cross-slip due to its higher stacking fault energy. The high-stress exponent of 8.8 and activation energy of $334 \mathrm{~kJ} \mathrm{~mol}^{-1}$ were simply explained by the increasing grain boundary in the initial body-center-cubic (bcc) phase. The dislocation configurations and microstructural evolution were not examined to confirm the validity of the proposed creep mechanism. Recently, He et al. [25,26] investigated the high-temperature plastic flow behavior of single-phase $\mathrm{FeCoNiMn}$ and precipitation-hardened $(\mathrm{FeCoNiCr})_{94} \mathrm{Ti}_{2} \mathrm{Al}_{4}$ HEAs using strain-rate-jump/stress increment tests at different temperatures $\left(750-900^{\circ} \mathrm{C}\right)$. In general, the deformation in these two alloys was divided into two regimes, dependent on the applied strain rate or testing temperatures. Specifically, the obtained higher stress exponent (6-9) and activation energy $\left(>600 \mathrm{~kJ} \mathrm{~mol}^{-1}\right)$ in the latter alloy were proposed to be associated with the strong interactions between dislocations and coherent precipitates, resulting in a threshold stress term in the flow constitutive equation [26]. It should be pointed out that the testing temperatures were up to $750-900{ }^{\circ} \mathrm{C}$ and far beyond the softening temperature $\left(\sim 600^{\circ} \mathrm{C}\right)$ of the investigated alloys [19]. From a scientific view, the strain-rate-jump or stress increment test method is inadequate using a single specimen at respective temperatures, as the microstructure during elevated-temperature plastic flow is generally not invariant. Moreover, such plastic-flow behavior is, to some extent, obviously different from creep deformation under a constant applied stress. Consequently, it is still necessary to systematically investigate the intermediate temperature (not higher than $600{ }^{\circ} \mathrm{C}$ ) creep deformation and examine the microstructural evolution for exploring the intrinsic deformation mechanism of HEAs.

In the present study, the tensile creep tests under constant stress were performed on multiple fine-grained $\mathrm{CoCrFeNiMn} \mathrm{HEA} \mathrm{specimens} \mathrm{in} \mathrm{the} \mathrm{temperature} \mathrm{range} \mathrm{of} 500-600{ }^{\circ} \mathrm{C}$. Specifically, some tests were interrupted at the steady-state stages and cooled quickly to reserve the crept microstructures for examining the microstructural evolution. The objective was to reveal the inherent relationship between microstructural evolution and creep properties of single-phase CoCrFeNiMn high-entropy alloy.

\section{Experimental Procedures}

Ingots with a nominal composition of $\mathrm{Co}_{20} \mathrm{Cr}_{20} \mathrm{Fe}_{20} \mathrm{Ni}_{20} \mathrm{Mn}_{20}$ (in atomic percentage) were prepared by vacuum induction melting the constituent elements with at least 99.9 mass $\%$ purity under argon atmosphere. To ensure chemical homogeneity, the ingots were re-melted at least five times and then drop-cast into a rectangular steel mold with a dimension of $120 \times 65 \times 10 \mathrm{~mm}^{3}$. The ingots were homogenized at $1100{ }^{\circ} \mathrm{C}$ for $24 \mathrm{~h}$ in a vacuum, followed by furnace cooling. Cold rolling was subsequently conducted on these ingots with a reduction of $40 \%$ in thickness, with several cross-rolling steps to ensure flatness. The rolled sheets were eventually annealed at $900{ }^{\circ} \mathrm{C}$ for $1 \mathrm{~h}$.

Flat dog-boned specimens with a dimension of $25 \mathrm{~mm}$ in gauge length and $5.6 \mathrm{~mm} \times 1.5 \mathrm{~mm}$ in cross-section were electric-discharge machined for creep tests. The specimens were mechanically ground to 2000-grid sand paper to remove surface asperities. Tensile creep tests were conducted 
at temperatures of 500, 550, and $600{ }^{\circ} \mathrm{C}$ under applied stresses of 140-400 MPa on a CSS-3905 multi-functional testing machine. The temperature was measured with a temperature accuracy of $\pm 1{ }^{\circ} \mathrm{C}$ by three thermocouples closely attached to the upper, middle, and lower sections of the specimen, respectively. The creep strain was continuously measured using a Linear Variable Differential Transducer (LVDT) extensometer with a strain resolution of $\pm 0.1 \mu \mathrm{m}$. The acquisition of strain-time data was accomplished by a computer, and data processing was conducted through a computer program. At least seven applied stress levels were chosen to obtain a wide range of creep rates for each testing temperature. Several specimens were subjected to interrupted tests at a steady-state stage and cooled quickly under the load using liquid nitrogen to freeze the structures produced during creep deformation.

The microstructural observation was conducted using optical microscopy $(\mathrm{OM})$ (AxioImager.A1m, Jena, Germany) after etching in an aqueous solution of $\mathrm{HCl}+\mathrm{H}_{2} \mathrm{O}_{2}+\mathrm{Cu}\left(\mathrm{NO}_{3}\right)_{2}$. The phase constitution was identified by X-ray diffraction (XRD) with $\mathrm{Cu}$-Ka radiation (PANalytical X'pert PRO, Almelo, Netherlands). Thin foils from the interrupted specimens for transmission electron microscope (TEM) observations were twin-jet electropolished in an ethanol solution containing 5\% perchloric acid at $-25^{\circ} \mathrm{C}$ and an applied voltage of $35 \mathrm{~V}$. TEM investigations were conducted on a JEOL JEM2100F microscope operated at $200 \mathrm{kV}$. Fracture surfaces were examined by a scanning electron microscope (SEM) (XL30 ESEM, Philip, Netherlands) equipped with an energy-dispersive spectrometer (EDS)).

\section{Results}

\subsection{Initial Microstructures}

Figure 1 shows the initial microstructures of the alloy in as-cast and annealed states prior to high-temperature creep deformation. It is evident that the cast alloy exhibits typical dendritic and interdendritic structures, caused by the segregation during the quick freezing process in the mold. After being cold-rolled and recrystallized, equiaxed and homogenous grain structures are obtained with many annealing twins visible inside the grains. The average grain size is evaluated to be approximately $25 \mu \mathrm{m}$. Energy-dispersive spectroscopy (EDS) analyses demonstrate that different grains have almost identical elemental compositions as $\mathrm{Cr}=19.9, \mathrm{Co}=19.9, \mathrm{Fe}=19.9, \mathrm{Ni}=19.8$, and $\mathrm{Mn}=19.5$ with a little loss of Mn due to its slight evaporation at an elevated temperature. As depicted by XRD patterns in Figure 1c, the alloy consists of a single fcc solid solution phase without precipitates or intermetallic compounds in both cast and recrystallized states. Furthermore, almost no peak shift is observed in the two states, with a cell parameter of $\mathrm{a}=0.361 \mathrm{~nm}$ for the fcc phase. The present results are different from those observed in the $\mathrm{Al}_{0.3} \mathrm{CoCrFeNi}$ HEA where precipitation of nanometer scale-ordered L12, B2, and sigma phases occurred in the case of different thermo-mechanical processing routes [27].

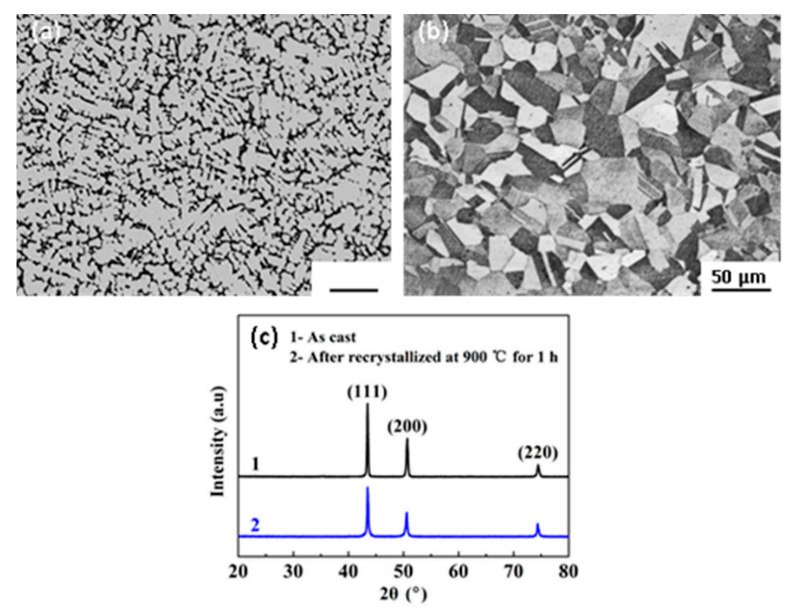

Figure 1. Microstructures of the alloy in different states. (a) As-cast, (b) thermo-mechanical treatment (cold-rolled and annealed at $900{ }^{\circ} \mathrm{C}$ for $1 \mathrm{~h}$ ), and (c) X-ray diffraction (XRD) patterns. 


\subsection{Steady-State Creep Deformation Behavior}

Figure 2 shows the selected creep curves of the alloy at 500-600 ${ }^{\circ} \mathrm{C}$ under different stress levels. It can be found that each of the individual curves exhibits a rather short primary creep stage and a relatively long steady-state region where the creep strain increases linearly with time, especially under lower stress levels. Necking and fracture of the specimens do occur, and hence, a tertiary stage of the curves is recorded in cases of high stress, where the creep rate accelerates with time until the final fracture occurs.
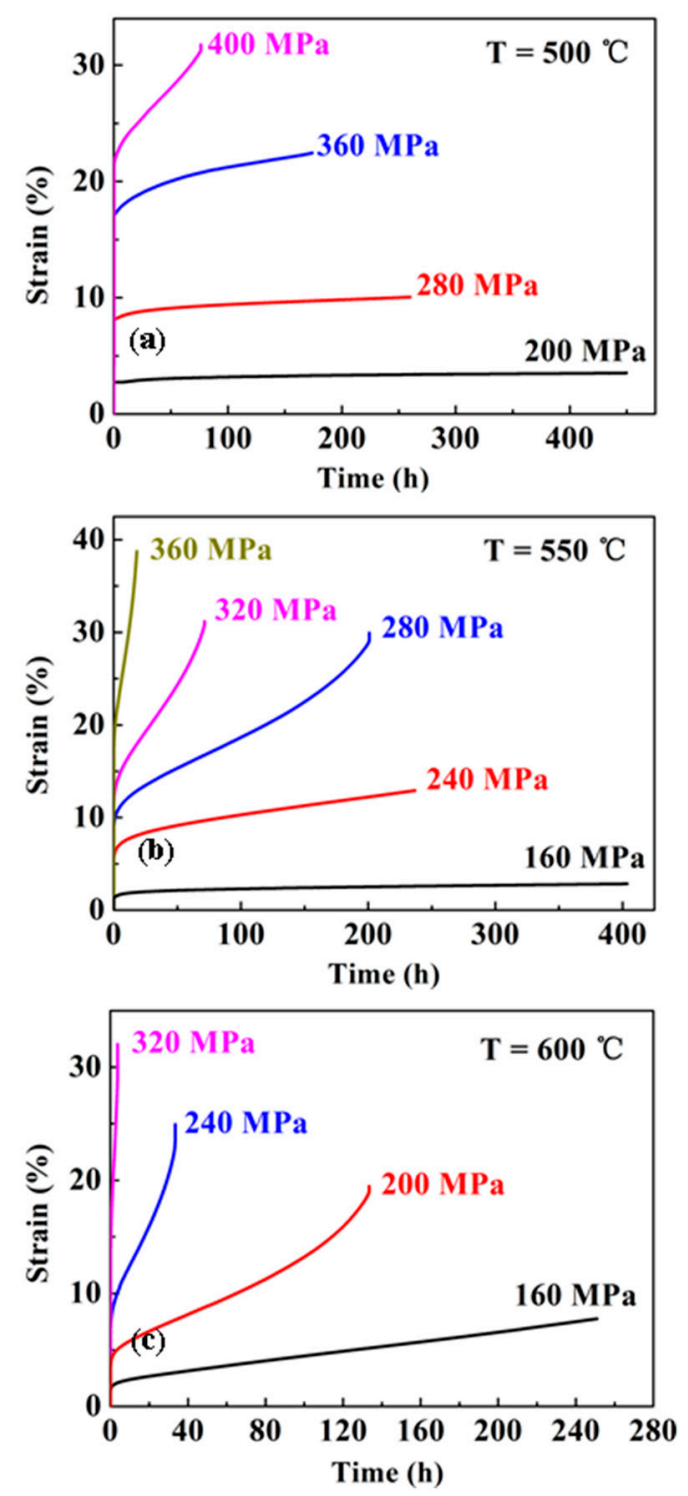

Figure 2. Selected creep strain versus time at (a) $500{ }^{\circ} \mathrm{C}$, (b) $550{ }^{\circ} \mathrm{C}$, and (c) $600{ }^{\circ} \mathrm{C}$.

It is generally accepted that the steady-state creep rate $\dot{\varepsilon}$ of metallic materials can be correlated with the applied stress $\sigma$ using the well-known power-law equation as follows [28]:

$$
\dot{\varepsilon}=\frac{A D_{0} G b}{k T}\left(\frac{b}{d}\right)^{p}\left(\frac{\sigma}{G}\right)^{n} \exp \left(-\frac{Q}{R T}\right)
$$

where $A$ is a material-dependent constant, $G$ the shear modulus, $b$ the Burgers vector, $D_{0}$ the frequency factor, $k$ the Boltzmann's constant, $T$ the absolute temperature, $d$ the grain size of polycrystalline materials, $Q$ the activation energy for creep deformation, and $p$ and $n$ the grain size and stress 
exponents, respectively. The stress exponent $n$ and activation energy value $Q$ are determined according to Equation (1) by plotting the steady-state creep rate against applied stress on a double logarithmic scale and the reciprocal of the absolute temperatures $1 / T$ at constant stress levels on a semi-logarithmic scale, as shown in Figures 3 and 4, respectively. It is evident that the data exhibit two distinct regions. In the low-stress region (subsequently denoted as LSR-region I), the stress exponent values vary in the range of 5 to 6 , and the average activation energy $Q$ takes a value of $268 \mathrm{~kJ} \mathrm{~mol}^{-1}$. On the contrary, in the high-stress region (subsequently denoted as HSR-region II), the stress exponents are in the range of $8.9-14$, and the activation energy is $Q=359-410 \mathrm{~kJ} / \mathrm{mol}$ with an average value of $380 \mathrm{~kJ} \mathrm{~mol}^{-1}$. The applied stress at which the transition occurred increased from 200 to $350 \mathrm{MPa}$, with the temperature decreasing from 600 to $500{ }^{\circ} \mathrm{C}$.

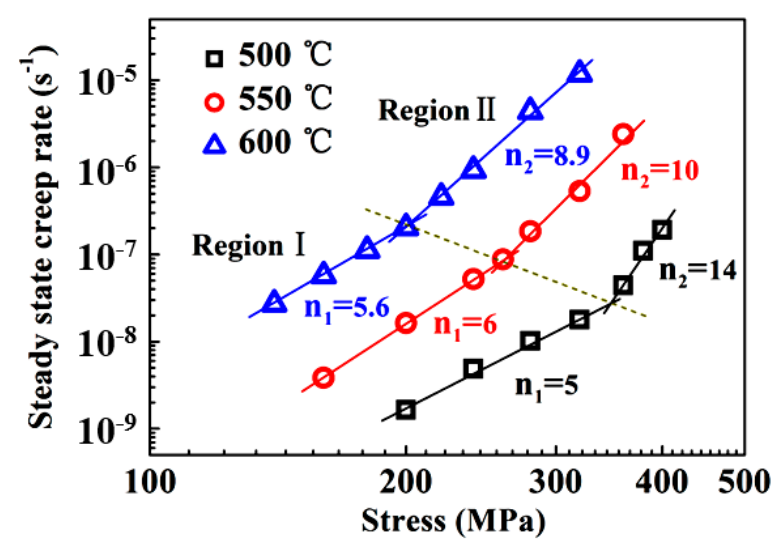

Figure 3. Dependence of creep rates on applied stress showing the transition in stress exponents.
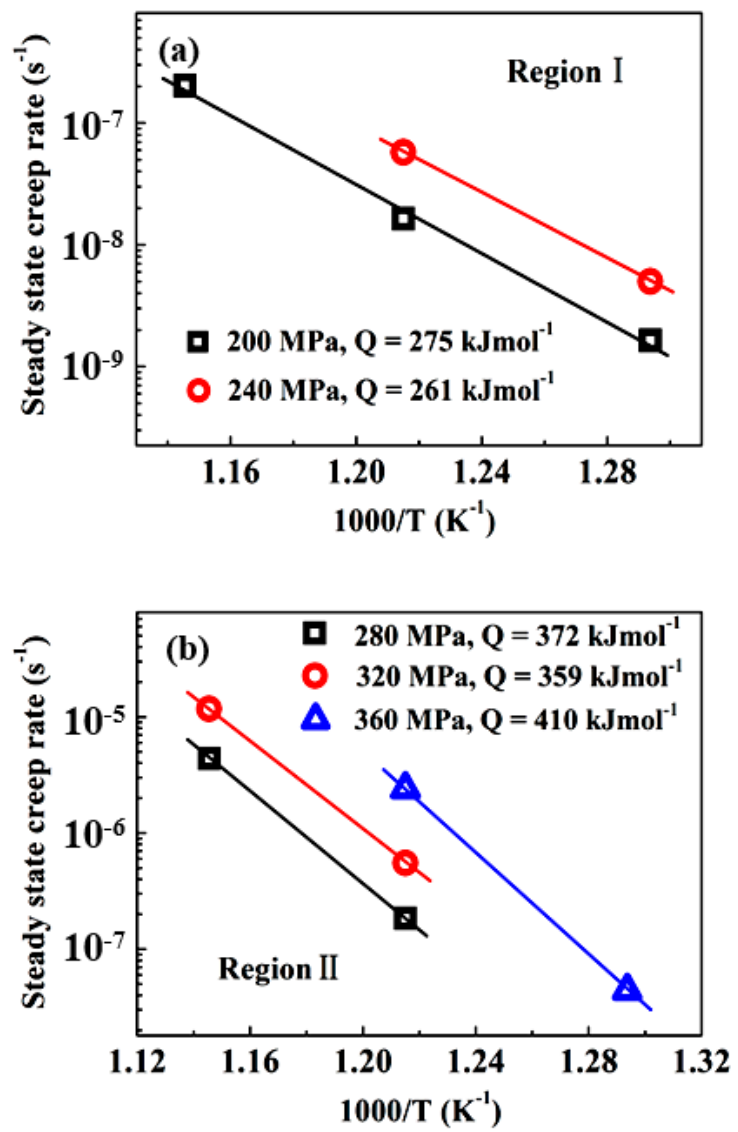

Figure 4. Arrhenius plot of steady-state creep rate versus temperature to determine the activation energy for (a) low-stress region I and (b) high-stress region II. 
It should be noted that the average activation energy of $268 \mathrm{~kJ} \mathrm{~mol}^{-1}$ in LSR-region I is only slightly lower than the range of activation energies for lattice diffusion of the constituent elements in the alloy (288-317 kJ mol${ }^{-1}$ [17]), and thus can be considered to be comparable to the lattice diffusion of the constituent elements in the alloy. In addition, this value is also quite close to those $\left(284-333 \mathrm{~kJ} \mathrm{~mol}^{-1}\right)$ reported for the steady-state flow behavior of this alloy at higher temperatures and lower stress levels [26]. The two characteristic parameters suggest a dislocation-climb mechanism operative in LSR. Nevertheless, the abnormally high stress exponent in HSR-region II is obviously beyond the values of 3 to 5 responsible for the dislocation glide or climb mechanism $[29,30]$ reported in some $\mathrm{Mg}$ [31], $\mathrm{Al}$ [32], and Ti [33,34] alloys. The underlying operative mechanism for HSR creep deformation in the present alloy will be addressed in the following section. In order to eliminate the influence of temperature on creep rate, the normalized creep rates $\dot{\varepsilon} k T \exp (Q / R T) / G$ versus the shear modulus-compensated stresses $\sigma / G$ were plotted in Figure 5, where activation energies $Q$ were taken to be $268 \mathrm{~kJ} \mathrm{~mol}^{-1}$ and $380 \mathrm{~kJ} \mathrm{~mol}^{-1}$ for region I and region II, respectively, and the shear modulus $G=85-16 /\left(e^{448 / T}-1\right)$ [35]. It is evident that almost all data points in the two stress regions at different temperatures can be represented by a single line with a respective slope of 5.5 and 10.6 for LSR and HSR. This strongly implies that creep deformation in both regions may be controlled by lattice diffusion of constituent elements in the alloy. However, it should be noted that the correlation between $\dot{\varepsilon} k T \exp (Q / R T) / G$ and $\sigma / G$ in HSR still yields an abnormally high stress exponent.
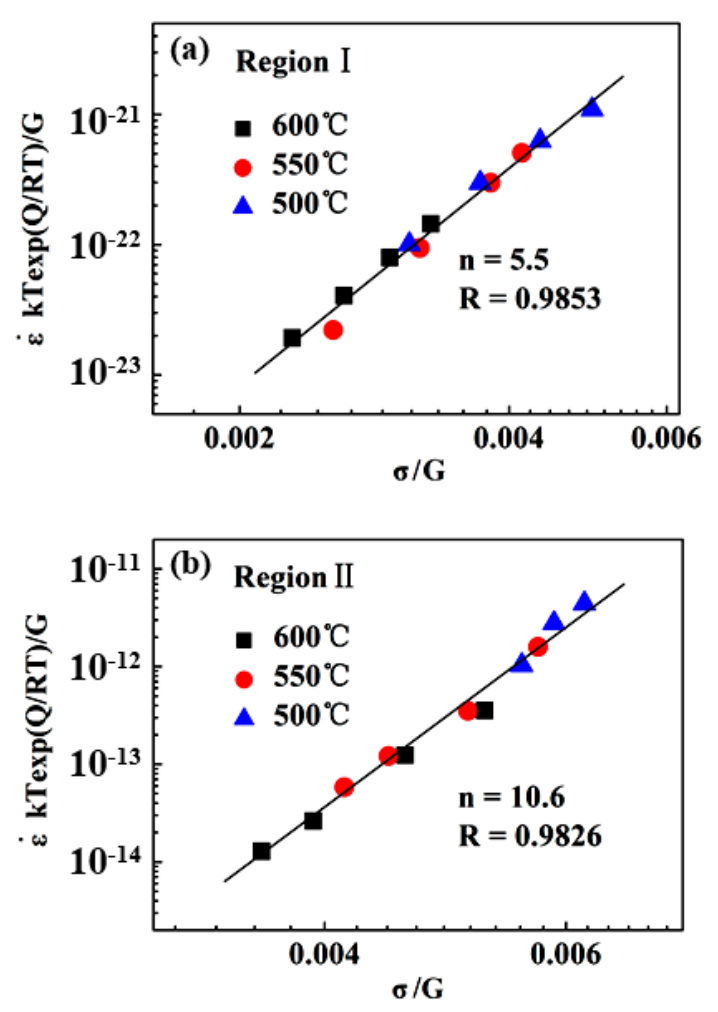

Figure 5. Normalized creep rate versus shear modulus-compensated stress for (a) low-stress region I and (b) high-stress region II.

\subsection{Crept Microstructures}

Figure 6 shows the microstructures of the interrupted samples at different temperatures and stress levels to illustrate the evolution of grain morphologies. Compared to the initial microstructure of the alloy, obvious coarsening can be observed when the specimens are subjected to low stress levels $\left(500{ }^{\circ} \mathrm{C} / 200 \mathrm{MPa}\right.$ and $\left.600{ }^{\circ} \mathrm{C} / 140 \mathrm{MPa}\right)$, as depicted in Figure $6 \mathrm{a}$,d. Similar grain coarsening phenomena are also visible at intermediate stress levels $\left(500{ }^{\circ} \mathrm{C} / 320 \mathrm{MPa}\right.$ and $\left.600{ }^{\circ} \mathrm{C} / 200 \mathrm{MPa}\right)$ near the transition stress indicated in Figure 3. However, the volume fraction of small equiaxed grains 
increases at the coarse grain boundaries (indicated by arrows in Figure $6 \mathrm{~b}, \mathrm{e}$ ), revealing strong evidence of the occurrence of dynamic recovery and recrystallization during creep deformation. Moreover, higher stress levels $\left(500{ }^{\circ} \mathrm{C} / 400 \mathrm{MPa}\right.$ and $\left.600{ }^{\circ} \mathrm{C} / 320 \mathrm{MPa}\right)$ lead to the formation of completely recrystallized and refined microstructures (Figure $6 \mathrm{c}, \mathrm{f}$ ). The resulting average grain sizes are statistically evaluated to be approximately 56,45 , and $22 \mu \mathrm{m}$ at $500{ }^{\circ} \mathrm{C}$, whereas 48,43 , and $31 \mu \mathrm{m}$ at $600{ }^{\circ} \mathrm{C}$ under different chosen stress levels.
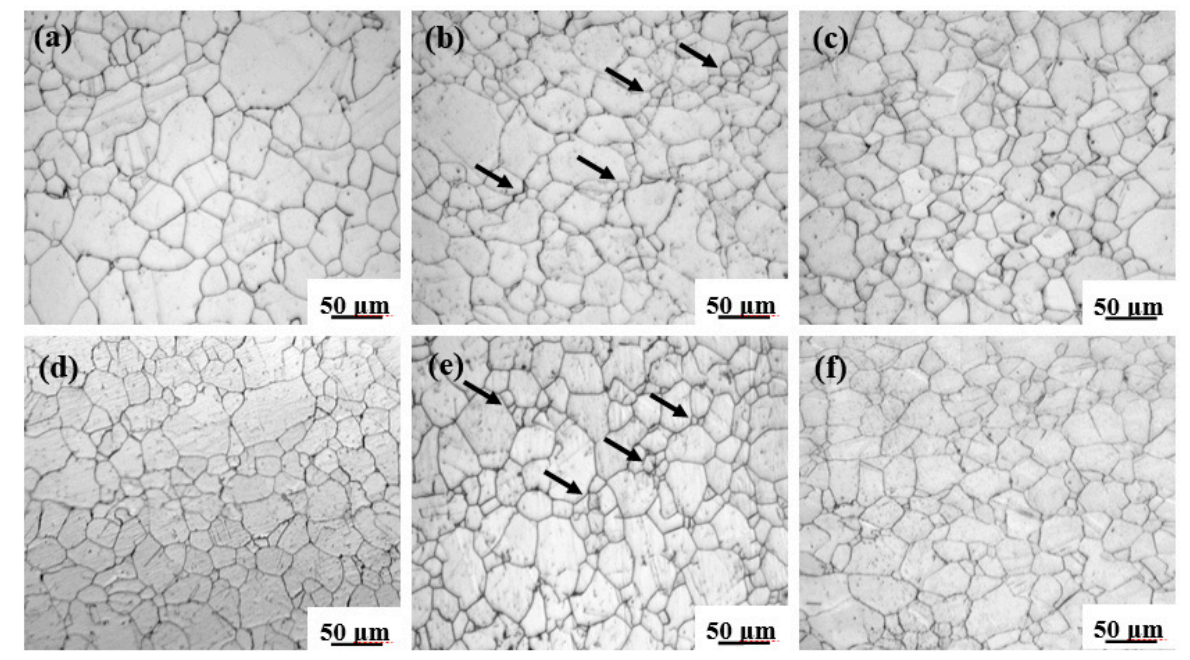

Figure 6. Optical microstructures showing the evolution of grain morphology after being crept at (a) $500{ }^{\circ} \mathrm{C} / 200 \mathrm{MPa}$, (b) $500{ }^{\circ} \mathrm{C} / 320 \mathrm{MPa}$, (c) $500{ }^{\circ} \mathrm{C} / 400 \mathrm{MPa}$, (d) $600{ }^{\circ} \mathrm{C} / 140 \mathrm{MPa}$, (e) $600{ }^{\circ} \mathrm{C} / 200 \mathrm{MPa}$, and (f) $600{ }^{\circ} \mathrm{C} / 320 \mathrm{MPa}$.

The dislocation substructures are shown in Figures 7-9, with selected area electron diffraction (SAED) patterns inserted to identify the precipitations. In general, the dislocation densities in HSR were distinctly higher than those in LSR at three testing temperatures. After being deformed at $500{ }^{\circ} \mathrm{C} / 200 \mathrm{MPa}$ (LSR), only a few short straight dislocation segments were displayed inside the grains (Figure 7a), and in particular, several lath-shaped areas were formed with closely-spaced dislocations arranged (Figure $7 \mathrm{~b}$ ). However, the substructures reveal increasing dislocation activity in LSR with increasing temperature, as the dislocations are extensively curved or even looped (Figures 8a and 9a). Apart from the limited number of alignments of pile-ups in Figure 8b, it is noted that cusped configurations are frequently observed inside grains with the bowed segments on either side. Such cusped configurations may be attributed to intrinsic pinning due to the occurrence of jogs along the screw dislocations [34]. In contrast, the dislocations in HSR exhibit a higher density of configurations. Numerous short straight segments are tangled and tend to form cell substructures at $500{ }^{\circ} \mathrm{C} / 400 \mathrm{MPa}$ (Figure $7 \mathrm{c}$ ). However, the dislocations at $550{ }^{\circ} \mathrm{C} / 360 \mathrm{MPa}$ show a relatively homogeneous distribution still with high densities of curved dislocations tangling with each other (Figure $8 \mathrm{c}$ ). The tangled dislocations at $600{ }^{\circ} \mathrm{C} / 320 \mathrm{MPa}$ are severely curved, with a large number of loops formed in a wide range of sizes (Figure $9 \mathrm{c}$ ).

Another striking aspect of microstructural evolution relies on the precipitation of dispersoids during a long-term deformation process at elevated temperatures. On the whole, considerable precipitates of irregular shape were predominantly observed at the grain boundaries in HSR. The sizes of these precipitates were within a range of 50-200 $\mathrm{nm}$ and increased with testing temperature. In cases of $500{ }^{\circ} \mathrm{C} / 400 \mathrm{MPa}$ and $600{ }^{\circ} \mathrm{C} / 320 \mathrm{MPa}$ (Figures $7 \mathrm{~d}$ and $9 \mathrm{~d}$ ), quantitative micro-EDS analysis indicates that the chemical compositions (at. \%) of the precipitates take almost identical values of $\mathrm{Cr}=26.6$, $\mathrm{Mn}=20.2, \mathrm{Fe}=18.9, \mathrm{Co}=17.5, \mathrm{Ni}=16.6$ (in at. \%) and a minor amount of carbon. The SAED pattern along the [011] zone axis exhibits intense diffraction spots from the fcc matrix, accompanied by weak spots from the precipitates. The crystal structure of these precipitates is identified as fcc $\mathrm{M}_{23} \mathrm{C}_{6}$ carbide with a lattice parameter of $1.06 \mathrm{~nm}$, which is consistent with both the general identifications of 
grain-boundary precipitates in austenitic steel [36] and the second phase observed in coarse-grained $\mathrm{CoCrFeNiMn}$ alloy after being subjected to prolonged exposures at $700{ }^{\circ} \mathrm{C}$ [37]. The tiny presence of carbon in the alloy may have originated from either the potential contamination of starting materials, or the melting system. Nevertheless, as depicted in Figures $8 \mathrm{~d}$ and $9 \mathrm{~b}$ for $550{ }^{\circ} \mathrm{C} / 360 \mathrm{MPa}$ and $600{ }^{\circ} \mathrm{C} / 140 \mathrm{MPa}$, the micro-EDS analysis demonstrates chemical compositions (at \%) of the precipitates with $\mathrm{Cr}=48.8, \mathrm{Mn}=15.5, \mathrm{Fe}=14.0, \mathrm{Co}=11.5$, and $\mathrm{Ni}=10.2$. The present results are quite consistent with previous reports for the prolonged annealing $\mathrm{CrMnFeCoNi}$ system [38,39], where the precipitates were identified as a quinary variant of the binary $\mathrm{Cr}-\mathrm{Fe} \sigma$ phase. The interplanar spacings are calculated to be $d_{1} / d_{2} / d_{3}=0.648 / 0.402 / 0.337 \mathrm{~nm}$ and show a satisfactory agreement with the values of $d_{1} / d_{2} / d_{3}=0.648 / 0.383 / 0.330 \mathrm{~nm}$ for $(1 \overline{1} 0) /(11 \overline{1}) /(20 \overline{1})$ lattice planes in the [112] zone axes for the $\sigma$-FeCrMo phase [40]. Accordingly, the precipitates in the $50{ }^{\circ} \mathrm{C} / 360 \mathrm{MPa}$ crept alloy are concluded to be $\mathrm{Cr}$-rich tetragonal $\sigma$ phase with lattice parameters of a $/ \mathrm{c}=0.916 / 0.509 \mathrm{~nm}$. Similarly, the weak spots along the [221] zone axes in the SAED pattern in Figure $9 b$ are also indicated to be very close to the Cr-rich $\sigma$ phase, with lattice parameters of $a / c=0.895 / 0.473 \mathrm{~nm}$.
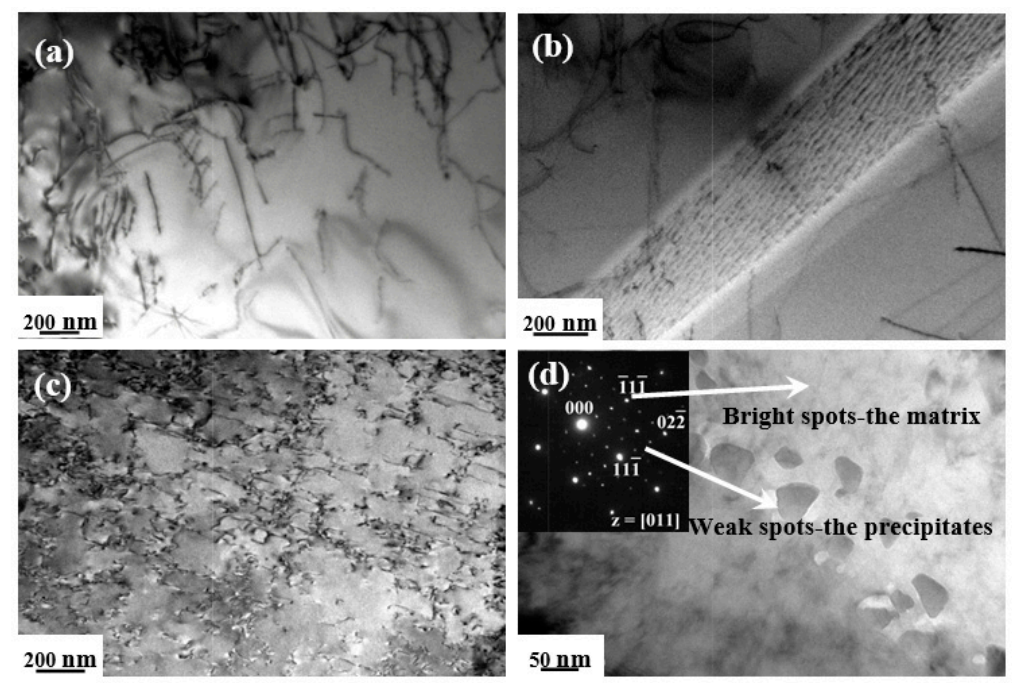

Figure 7. Transmission electron microscope (TEM) images of dislocation substructures in the interrupted specimens after being crept at $500{ }^{\circ} \mathrm{C}$ under (a) and (b) $200 \mathrm{MPa}$ (low-stress region (LSR)); (c) and (d) $400 \mathrm{MPa}$ (high-stress region (HSR)).
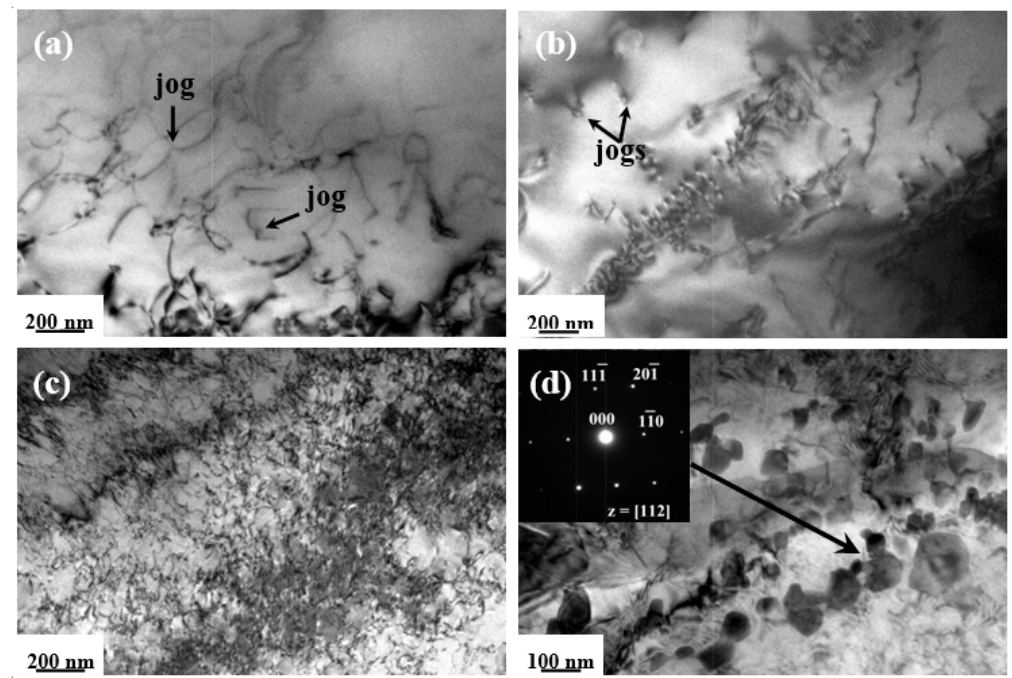

Figure 8. TEM images of dislocation substructures in the interrupted specimens after being crept at $550{ }^{\circ} \mathrm{C}$ under (a) and (b) $160 \mathrm{MPa}$ (LSR); (c) and (d) $360 \mathrm{MPa}$ (HSR). 

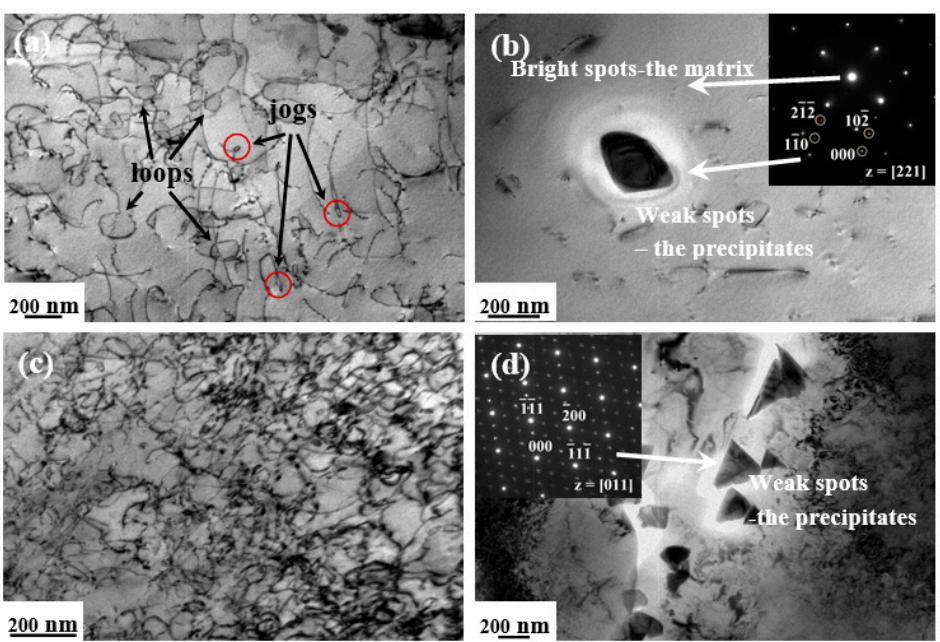

Figure 9. TEM images of dislocation substructures in the interrupted specimens after being crept at $600{ }^{\circ} \mathrm{C}$ under (a) and (b) $140 \mathrm{MPa}$ (LSR); (c) and (d) $320 \mathrm{MPa}$ (HSR).

\subsection{Fractographs}

All the fractographs in Figure 10 for HSR from $500{ }^{\circ} \mathrm{C}$ to $600{ }^{\circ} \mathrm{C}$ exhibit typical ductile rupture, where both the width and depth of dimples increase with temperature. However, slip striations around the dimples become notable at $600^{\circ} \mathrm{C}$. Meanwhile, a small number of particles identified as Mn-containing oxides by EDS are visible on the fracture surfaces, which is attributed to an in-situ oxidation during fracture process [26]. It is worth noting that the crept samples fracture in a ductile transgranular manner at high stress, which is contrary to common knowledge, as large amounts of brittle are generally considered to be destructive to the stability of grain boundaries during the tertiary creep stage [41,42]. The ductile creep failure may be associated with the dislocation interactions during high-temperature deformation, which contribute to the progressive generation of vacancies and nucleation of voids.
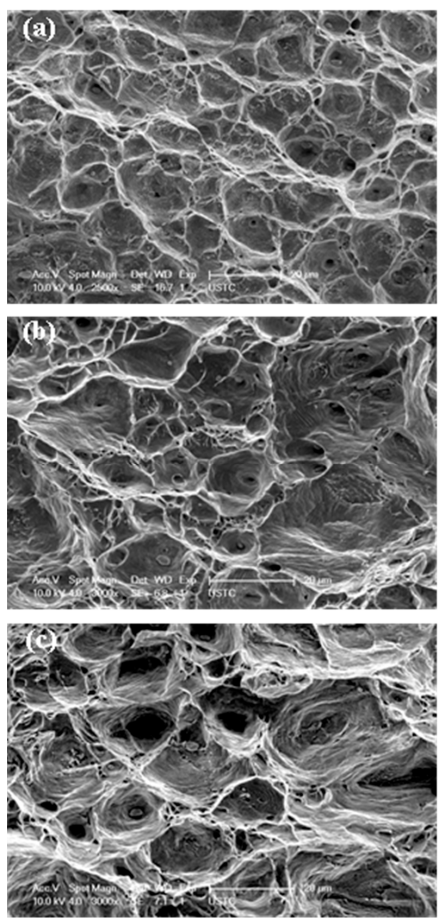

Figure 10. Microstructural features of the fracture surfaces after being deformed at high stress levels. (a) $500{ }^{\circ} \mathrm{C} / 400 \mathrm{MPa}$, (b) $550{ }^{\circ} \mathrm{C} / 360 \mathrm{MPa}$, and (c) $600{ }^{\circ} \mathrm{C} / 320 \mathrm{MPa}$. 


\section{Discussion}

The observed jog configurations are indicative of a dislocation climb process, and thus the stress-assisted dislocation climb controlled by lattice diffusion may be the operative creep mechanism of the present high-entropy alloy in LSR. Contrary to LSR, creep deformation in HSR exhibits abnormally high stress exponents of 8.9-14 and an average activation energy of $380 \mathrm{~kJ} \mathrm{~mol}^{-1}$. Combined with the dislocation configurations in Figures $8 c$ and $9 c$, the same creep mechanism may also be considered rate-controlling. The unusually high stress exponents and activation energy in several traditional alloys have been frequently described using the power-law breakdown equation [43-46]. However, no deviation from the linear relationship on double-logarithmic curves of $\log \dot{\varepsilon} \sim \log \sigma$ were observed, and therefore, the power-law breakdown assumption may be inappropriate for the present alloy.

It is documented that dynamic recrystallization during the creep process could cause an increase in the stress exponent [47-49]. Recrystallization is generally accompanied by intense diffusion of solutes, resulting in a refined-grain microstructure and a larger opportunity for grain boundary sliding. Under such circumstances, the creep rate would increase with decreasing grain size [50]. As shown in Figure 6, obvious dynamic recrystallization occurred in the present CoCrFeNiMn alloy in HSR. In fact, low stacking-fault energy of alloys is conducive to promoting recrystallization [51]. Based on Equation (1) where $p$ is generally equal to 2 for a dislocation-controlled creep, an increase in the stress exponent $\Delta n$ due to dynamic recrystallization is expressed as [47]:

$$
\Delta n=n_{a p p}-n=\frac{2 \ln \left(d_{1} / d_{2}\right)}{\ln \left(\sigma_{2} / \sigma_{1}\right)}
$$

where $n_{\text {app }}$ is the experimentally measured apparent stress exponent, $n$ is the stress exponent prior to the occurrence of recrystallization, $d_{1}$ and $d_{2}$ denote the average grains size before and after dynamic recrystallization, and $\sigma_{1}$ and $\sigma_{2}$ are the corresponding stress levels. Using the relevant evaluated grain sizes, the $\Delta n$ values were calculated to be 6.5 and 1.4 for $500{ }^{\circ} \mathrm{C}$ and $600{ }^{\circ} \mathrm{C}$, respectively. The corresponding modified stress exponents $n$ then fall down to 7.5 . However, this value is still higher than those for traditional solid solution alloys, which implies that the sole recrystallization is insufficient and additional mechanisms should be involved to be responsible for the entire increase in stress exponents.

TEM observations provide clear evidence of dynamic precipitation in HSR. As a result, precipitation hardening may have contributed to the high stress exponents [25]. In general, the precipitates are predominantly formed along the grain boundaries and would exert a boundary obstacle stress $\sigma_{b o}$, which prevent the annihilation of moving dislocations at the boundaries. The stress controlling the dislocation velocity is reduced to an effective value obtained by subtracting the stress necessary for overcoming precipitates from the applied stress. Equation (1) is then replaced by [52,53]:

$$
\dot{\varepsilon}=\frac{A D_{0} G b}{k T}\left(\frac{b}{d}\right)^{p}\left(\frac{\sigma-\sigma_{b 0}}{G}\right)^{n} \exp \left(-\frac{Q}{R T}\right)
$$

By re-plotting the double-logarithm relationship between $\dot{\varepsilon} / \exp (-Q / R T)$ and $\left(\sigma-\sigma_{b o}\right) / G$ in HSR, the stress exponents can then be decreased by subtracting the precipitation-hardening portion. Unfortunately, it is difficult to precisely estimate the values of boundary obstacle stress and the decrease in the stress exponent, due to the ambiguous interaction between dynamic precipitation and recrystallization. Nevertheless, combinative effects of precipitation hardening and recrystallization can provide reasonable insights into the intrinsic reason for the abnormal stress exponents and activation energy for creep in $\mathrm{CoCrFeNiMn}$ alloy. Moreover, the estimated abnormal activation energy in HSR might also stem partially from precipitation hardening [22]. The nano-sized dispersoids could effectively fasten the grain boundaries, and thus extra activation energy is needed to overcome the barriers for recrystallization and further growth of grains. In addition, the samples experience drastic 
plastic deformation in a short time to establish a constant stress state for subsequent creep deformation. As a result, some grains are severely elongated, which, in turn, exerts an extra influence on increasing the barriers for dynamic recovery and recrystallization.

\section{Conclusions}

The intermediate-temperature creep behavior and microstructural evolution of $\mathrm{CoCrFeNiMn}$ HEA have been studied. Optical micrographs and TEM images of the dislocation substructure after creep deformation revealed the effects of dynamic recrystallization and dynamic precipitation on the deformation mechanisms. The following conclusions can be drawn:

1. An obvious transition in stress exponent and average activation energy was observed: At low stresses, the values were approximately 5 to 6 and $268 \mathrm{~kJ} / \mathrm{mol}$, whereas at high-stress regions, the corresponding values were $8.9-14$ and $380 \mathrm{~kJ} / \mathrm{mol}$. Stress-assisted dislocation climb controlled by lattice diffusion is suggested as a possible rate-dominating mechanism at low stresses.

2. At high stresses, obvious dynamic recrystallization occurred, leading to the refinement of average grain size. Simultaneously, nano-sized $\mathrm{M}_{23} \mathrm{C}_{6}$ carbides and the $\mathrm{Cr}$-rich tetragonal $\sigma$ phase were dynamically precipitated. High density of tangled and curved dislocation substructures was observed.

3. The anomalously high stress exponent and activation energy in HSR were attributed to the combinative effects of dynamic recrystallization and precipitation. In particular, the precipitates act as barriers for dislocation motion via producing boundary obstacle stress, resulting in high activation energy for creep deformation. However, lattice-diffusion controlled dislocation climb is still responsible for the deformation mechanism in HSR.

Author Contributions: L.P. initiated this research project. C.C. performed the creep tests. T.T. and Y.H. prepared the entropy alloy. J.F. performed the microstructural characterization and thermal-mechanical processing under the supervision of P.G., H.H. and L.P. All authors discussed the results and approved the final manuscript.

Funding: This research was funded by the National Natural Science Foundation of China (11572306) and the Fundamental Research Funds for Central Universities (WK2090050040).

Conflicts of Interest: The authors declare no conflict of interest.

\section{References}

1. Zhang, Y.; Zuo, T.T.; Tang, Z.; Gao, M.C.; Dahmen, K.A.; Liaw, P.K.; Lu, Z.P. Microstructures and properties of high-entropy alloys. Prog. Mater. Sci. 2014, 61, 1-93. [CrossRef]

2. Sheng, H.F.; Gong, M.; Peng, L.M. Microstructural characterization and mechanical properties of an $\mathrm{Al}_{0.5} \mathrm{CoCrFeCuNi}$ high-entropy alloy in as-cast and heat-treated/quenched conditions. Mater. Sci. Eng. A 2013, 567, 14-20. [CrossRef]

3. Borkar, T.; Gwalani, B.; Choudhuri, D.; Mikler, C.V.; Yannetta, C.J.; Chen, X.; Ramanujan, R.V.; Styles, M.J.; Gibson, M.A.; Banerjee, R. A combinatorial assessment of $\mathrm{Al}_{\mathrm{x}} \mathrm{CrCuFeNi}_{2}(0<\mathrm{x}<1.5)$ complex concentrated alloys: Microstructure, microhardness, and magnetic properties. Acta Mater. 2016, 116, 63-76.

4. Manzoni, A.M.; Haas, S.; Daoud, H.; Glatzel, U.; Förster, C.; Wanderka, N. Tensile behavior and evolution of the phases in the $\mathrm{Al}_{10} \mathrm{CO}_{25} \mathrm{Cr}_{8} \mathrm{Fe}_{15} \mathrm{Ni}_{36} \mathrm{Ti}_{6}$ compositionally complex/high entropy alloy. Entropy 2018, 20, 646. [CrossRef]

5. Miracle, D.B.; Senkov, O.N. A critical review of high entropy alloys and related concepts. Acta Mater. 2017, 122, 448-511. [CrossRef]

6. Chen, R.R.; Qin, G.; Zheng, H.T.; Wang, L.; Su, Y.Q.; Chiu, Y.L.; Ding, H.S.; Guo, J.J.; Fu, H.Z. Composition design of high entropy alloys using the valence electron concentration to balance strength and ductility. Acta Mater. 2018, 144, 129-137. [CrossRef]

7. Bu, Y.Q.; Peng, S.Y.; Wu, S.W.; Wei, Y.J.; Wang, G.; Liu, J.B.; Wang, H.T. Unconventional deformation behaviours of nanoscaled high-entropy alloys. Entropy 2018, 20, 778. [CrossRef]

8. Otto, F.; Yang, Y.; Bei, H.; George, E.P. Relative effects of enthalpy and entropy on the phase stability of equiatomic high-entropy alloys. Acta Mater. 2013, 61, 2628-2638. [CrossRef] 
9. Zhang, Y.; Zhou, Y.J.; Lin, J.P.; Chen, G.L.; Liaw, P.K. Solid-solution phase formation rules for multi-component alloys. Adv. Eng. Mater. 2008, 10, 534-538. [CrossRef]

10. Ji, W.; Wang, W.M.; Wang, H.; Zhang, J.Y.; Wang, Y.C.; Zhang, F.; Fu, Z.Y. Alloying behavior and novel properties of $\mathrm{CoCrFeNiMn}$ high-entropy alloy fabricated by mechanical alloying and spark plasma sintering. Intermetallics 2015, 56, 24-27. [CrossRef]

11. Sathiaraj, G.D.; Bhattacharjee, P.P. Analysis of microstructure and microtexture during grain growth in low stacking fault energy equiatomic CoCrFeMnNi high entropy and Ni-60 wt. \% Co alloys. J. Alloys Compd. 2015, 637, 267-276. [CrossRef]

12. Tasan, C.C.; Deng, Y.; Pradeep, K.G.; Yao, M.J.; Springer, H.; Raabe, D. Composition dependence of phase stability, deformation mechanisms, and mechanical properties of the CoCrFeMnNi high-entropy alloy system. JOM 2014, 66, 1993-2001. [CrossRef]

13. Varvenne, C.; Luque, A.; Curtin, W.A. Theory of strengthening in fcc high entropy alloys. Acta Mater. 2016, 118, 164-176. [CrossRef]

14. Wu, Z.; Bei, H.; Otto, F.; Pharr, G.M.; George, E.P. Recovery, recrystallization, grain growth and phase stability of a family of FCC-structured multi-component equiatomic solid solution alloys. Intermetallics 2014, 46, 131-140. [CrossRef]

15. Liu, W.H.; Wu, Y.; He, J.Y.; Nieh, T.G.; Lu, Z.P. Grain growth and the Hall-Petch relationship in a high-entropy FeCrNiCoMn alloy. Scr. Mater. 2013, 68, 526-529. [CrossRef]

16. Otto, F.; Hanold, N.L.; George, E.P. Microstructural evolution after thermomechanical processing in an equiatomic, single-phase CoCrFeMnNi high-entropy alloy with special focus on twin boundaries. Intermetallics 2014, 54, 39-48. [CrossRef]

17. Tsai, K.Y.; Tsai, M.H.; Yeh, J.W. Sluggish diffusion in Co-Cr-Fe-Mn-Ni high-entropy alloys. Acta Mater. 2013, 61, 4887-4897. [CrossRef]

18. Gludovatz, B.; Hohenwarter, A.; Catoor, D.; Chang, E.H.; George, E.P.; Ritchie, R.O. A fracture-resistant high-entropy alloy for cryogenic applications. Science 2014, 345, 1153-1158. [CrossRef]

19. Otto, F.; Dlouhý, A.; Somsen, C.; Bei, H.; Eggeler, G.; George, E.P. The influences of temperature and microstructure on the tensile properties of a CoCrFeMnNi high-entropy alloy. Acta Mater. 2013, 61, 5743-5755. [CrossRef]

20. Gali, A.; George, E.P. Tensile properties of high- and medium-entropy alloys. Intermetallics 2013, 39, 74-78. [CrossRef]

21. Wu, Z.; Bei, H.; Pharr, G.M.; George, E.P. Temperature dependence of the mechanical properties of equiatomic solid solution alloys with face-centered cubic crystal structures. Acta Mater. 2014, 81, 428-441. [CrossRef]

22. Hong, S.I.; Moon, J.S.; Hong, K.; Kim, H.S. Thermally activated deformation and the rate controlling mechanism in CoCrFeMnNi high entropy alloy. Mater. Sci. Eng. A 2017, 682, 569-576. [CrossRef]

23. Wu, Z.; Gao, Y.; Bei, H. Thermal activation mechanisms and Labusch-type strengthening analysis for a family of high-entropy and equiatomic solid-solution alloys. Acta Mater. 2016, 120, 108-119. [CrossRef]

24. Cao, T.; Shang, J.; Zhao, J.; Cheng, C.; Wang, R.; Wang, H. The influence of Al elements on the structure and the creep behavior of $\mathrm{Al}_{\mathrm{x}} \mathrm{CoCrFeNi}$ high entropy alloys. Mater. Lett. 2016, 164, 344-347. [CrossRef]

25. He, J.Y.; Zhu, C.; Zhou, D.Q.; Liu, W.H.; Nieh, T.G.; Lu, Z.P. Steady state flow of the FeCoNiCrMn high entropy alloy at elevated temperatures. Intermetallics 2014, 55, 9-14. [CrossRef]

26. He, J.Y.; Wang, H.; Wu, Y.; Liu, X.J.; Nieh, T.G.; Lu, Z.P. High-temperature plastic flow of a precipitation-hardened FeCoNiCr high entropy alloy. Mater. Sci. Eng. A 2017, 686, 34-40. [CrossRef]

27. Gwalani, B.; Gorsse, S.; Choudhuri, D.; Styles, M.; Zheng, Y.F.; Mishra, R.S.; Banerjee, R. Modifying transformation pathways in high entropy alloys or complex concentrated alloys via thermo-mechanical processing. Acta Mater. 2018, 153, 169-185. [CrossRef]

28. Mukherjee, A.K.; Bird, J.E.; Dorn, J.E. Experimental Correlations for High-Temperature Creep; Technical Report; California Univ., Lawrence Radiation Lab.: Berkeley, CA, USA, 1968.

29. Kassner, M.E.; Pérez-Prado, M.T. Five-power-law creep in single phase metals and alloys. Prog. Mater. Sci. 2000, 45, 1-102. [CrossRef]

30. Tobolová, Z.; Čadek, J. An interpretation of steady state creep. Philos. Mag. 1972, 26, 1419-1428. [CrossRef]

31. Naghdi, F.; Mahmudi, R. The microstructure and creep characteristics of cast $\mathrm{Mg}-4 \mathrm{Zn}-0.5 \mathrm{Ca}$ and Mg-4Zn-0.5Ca-2RE alloys. Mater. Sci. Eng. A 2014, 610, 315-325. [CrossRef] 
32. Chaudhury, P.K.; Farghalli, A.M. Creep and ductility in an Al-Cu solid-solution alloy. Metall. Trans. A 1987, 18, 2105-2113. [CrossRef]

33. Nie, X.; Liu, H.Q.; Zhou, X.Z.; Yi, D.Q.; Huang, B.Y.; Hu, Z.; Xu, Y.F.; Yang, Q.; Wang, D.C.; Gao, Q. Creep of Ti-5Al-5Mo-5V-1Fe-1Cr alloy with equiaxed and lamellar microstructures. Mater. Sci. Eng. A 2016, 651, $37-44$. [CrossRef]

34. Viswanathan, G.B.; Karthikeyan, S.; Hayes, R.W.; Mills, M.J. Creep behaviour of Ti-6Al-2Sn-4Zr-2Mo: II. Mechanisms of deformation. Acta Mater. 2002, 50, 4965-4980. [CrossRef]

35. Laplanche, G.; Gadaud, P.; Horst, O.; Otto, F.; Eggeler, G.; George, E.P. Temperature dependencies of the elastic moduli and thermal expansion coefficient of an equiatomic, single-phase CoCrFeMnNi high-entropy alloy. J. Alloys Compd. 2015, 623, 348-353. [CrossRef]

36. Heczko, M.; Polák, J.; Kruml, T. Microstructure and dislocation arrangements in Sanicro 25 steel fatigued at ambient and elevated temperatures. Mater. Sci. Eng. A 2017, 680, 168-181. [CrossRef]

37. Pickering, E.J.; Muñoz-Moreno, R.; Stone, H.J.; Jones, N.G. Precipitation in the equiatomic high-entropy alloy CrMnFeCoNi. Scr. Mater. 2016, 113, 106-109. [CrossRef]

38. Otto, F.; Dlouhý, A.; Pradeep, K.G.; Kuběnová, M.; Raabe, D.; Eggeler, G.; George, E.P. Decomposition of the single-phase high-entropy alloy $\mathrm{CrMnFeCoNi}$ after prolonged anneals at intermediate temperatures. Acta Mater. 2016, 112, 40-52. [CrossRef]

39. Zhu, Z.G.; Ma, K.H.; Yang, X.; Shek, C.H. Annealing effect on the phase stability and mechanical properties of $(\mathrm{FeNiCrMn})_{(100-\mathrm{x})} \mathrm{Co}_{\mathrm{x}}$ high entropy alloys. J. Alloys Compd. 2017, 695, 2945-2950. [CrossRef]

40. Shen, Y.Z.; Zhou, X.L.; Shi, T.T.; Huang, X.; Shang, Z.X.; Liu, W.W.; Ji, B.; Xu, Z.Q. Sigma phases in an $11 \% \mathrm{Cr}$ ferritic/martensitic steel with the normalized and tempered condition. Mater. Charact. 2016, 122, 113-123. [CrossRef]

41. Han, W.Y.; Yang, G.Y.; Xiao, L.; Li, J.H.; Jie, W.Q. Creep properties and creep microstructure evolution of Mg-2.49Nd-1.82Gd-0.19Zn-0.4Zr alloy. Mater. Sci. Eng. A 2017, 684, 90-100. [CrossRef]

42. Zhang, Z.; Hu, Z.F.; Tu, H.Y.; Schmauder, S.; Wu, G.X. Microstructure evolution in HR3C austenitic steel during long-term creep at $650^{\circ}$ C. Mater. Sci. Eng. A 2017, 681, 74-84. [CrossRef]

43. Sherby, O.D.; Burke, P.M. Mechanical behavior of crystalline solids at elevated temperature. Prog. Mater Sci. 1968, 13, 323-390. [CrossRef]

44. Srikant, G.; Marple, B.; Charit, I.; Murty, K. Characterization of stress rupture behavior of commercial-purity-Ti via burst testing. Mater. Sci. Eng. A 2007, 463, 203-207. [CrossRef]

45. Tanhaee, Z.; Mahmudi, R. The microstructure and creep characteristics of cast Mg-3Si and Mg-3Si-1Gd alloys. Mater. Sci. Eng. A 2016, 673, 148-157. [CrossRef]

46. Raj, S.V. Power-law and exponential creep in class $M$ materials: Discrepancies in experimental observations and implications for creep modeling. Mater. Sci. Eng. A 2002, 322, 132-147. [CrossRef]

47. Allameh, S.M. High creep exponents in a nearly-lamellar $\gamma$-based titanium aluminide intermetallic. J. Mater. Sci. 2001, 36, 3539-3547. [CrossRef]

48. Luan, Q.D.; Duan, Q.Q.; Wang, X.G.; Liu, J.; Peng, L.M. Tensile properties and high temperature creep behavior of microalloyed Ti-Ti3Al-Nb alloys by directional solidification. Mater. Sci. Eng. A 2010, 527, 4484-4496. [CrossRef]

49. Rettberg, L.H.; Pollock, T.M. Localized recrystallization during creep in nickel-based superalloys GTD444 and René N5. Acta Mater. 2014, 73, 287-297. [CrossRef]

50. Ning, Z.L.; Liu, H.H.; Cao, F.Y.; Wang, S.T.; Sun, J.F.; Qian, M. The effect of grain size on the tensile and creep properties of Mg-2.6Nd-0.35Zn-xZr alloys at $250^{\circ} \mathrm{C}$. Mater. Sci. Eng. A 2013, 560, 163-169. [CrossRef]

51. Stepanov, N.D.; Shaysultanov, D.G.; Yurchenko, N.Y.; Zherebtsov, S.V.; Ladygin, A.N.; Salishchev, G.A.; Tikhonovsky, M.A. High temperature deformation behavior and dynamic recrystallization in $\mathrm{CoCrFeNiMn}$ high entropy alloy. Mater. Sci. Eng. A 2015, 636, 188-195. [CrossRef]

52. Zhang, J.S.; Li, P.E.; Chen, W.X.; Jin, J.Z. Grain boundary precipitation strengthening in high temperature creep of Fe-15Cr-25Ni alloys. Scr. Metall. 1989, 23, 547-551. [CrossRef]

53. Li, P.E.; Zhang, J.S.; Wang, F.G.; Jin, J.Z. Influence of Intergranular carbide density and grain size on creep of Fe-15Cr-25Ni alloys. Metall. Trans. A 1991, 23, 1379-1381. [CrossRef]

(C) 2018 by the authors. Licensee MDPI, Basel, Switzerland. This article is an open access article distributed under the terms and conditions of the Creative Commons Attribution (CC BY) license (http:/ / creativecommons.org/licenses/by/4.0/). 